\title{
GMR
}

\section{Allele frequencies in Azuay Population in Ecuador}

\author{
P.P. Orellana ${ }^{1}$, C.F. Andrade ${ }^{1}$, C.L. Arciniegas ${ }^{2}$ and G.C. Iannacone ${ }^{3}$ \\ ${ }^{1}$ Academic Unit of Health and Welfare, Odontology Career, \\ Laboratory of Molecular Biology and Genetics, \\ Catholic University of Cuenca, Cuenca, Ecuador \\ ${ }^{2}$ Academic Unit of Social Sciences, Journalism, Information and Law, \\ Law Career, Catholic University of Cuenca, Cuenca, Ecuador \\ ${ }^{3}$ Laboratory of Molecular Biology and Genetics, \\ Institute of Legal Medicine, Lima, Peru \\ Correspondig autor: P.P. Orellana \\ E-mail: porellana@ucacue.edu.ec
}

Genet. Mol. Res. 16 (3): gmr16039797

Received August 11, 2017

Accepted September 15, 2017

Published September 27, 2017

DOI http://dx.doi.org/10.4238/gmr16039797

Copyright (C) 2017 The Authors. This is an open-access article distributed under the terms of the Creative Commons Attribution ShareAlike (CC BY-SA) 4.0 License.

ABSTRACT. One hundred and eighty-two samples of unrelated people
who requested the paternity test at the Molecular Biology and Genetics
Laboratory of the Catholic University of Cuenca-Ecuador in the
province of Azuay were studied, except for the D1S1656 (180 samples)
and SE33 (89 samples) markers. The STRs D22S1045, D3S1358,
$V W A, D 16 S 539, D 2 S 1338, D 8 S 1179, D 21 S 11, D 18 S 51, D 19 S 433$,
TH01, FGA,D1S1656,D12S391,D10S1248,D2S441, and SE33 were
typed from blood samples, amplifying the DNA by polymerase chain
reactions and electrophoresis. The allele frequencies were estimated by
simple counting and the impartial heterozygosity was also calculated.
The Hardy-Weinberg equilibrium theory was studied. In the results
obtained with the analyzed markers, the largest number of alleles can
be observed in the markers with the highest polymorphic information
content (PIC): D21S11, D16S539, D2S1338, D19S433, D18S51, FGA,

Genetics and Molecular Research 16 (3): gmr16039797 
D1S1656, and D12S391. In addition, SE33 was analyzed in certain samples, showing as result a high PIC, in fact, the highest one because of its great polymorphisc characteristic. Likewise, these markers are the ones providing the highest probability of discrimination and the lowest probability of coincidence.

Key words: Short tandem repeat; Allele frequencies, Azuay population

\section{INTRODUCTION}

Short tandem repeat (STR) markers were first described as effective tools for human identity testing in the early 1990's (Butler, 2006). Over the past decade, the human identity testing community has settled on a set of core STR loci that are widely used for DNA typing applications (Butler, 2006). The usefulness of genetic markers for identity testing and paternity analysis is based on known allele frequencies for the genetic markers analyzed (Cifuentes et al., 2008). STR loci are short, repetitive sequences (3-7 base pairs in length) distributed throughout the human genome (Butler, 2005). A variety of commercial kits enable robust amplification of these core STR loci (Butler, 2006). NGM is a kit of PCR amplification of fifteen STR: D22S1045, D3S1358, VWA, D16S539, D2S1338, D8S1179, D21S11, D18S51, D19S433, TH01, FGA, D1S1656,D12S391,D10S1248, and D2S441, and the gender determination locus, Amelogenin (Applied Biosystems, 2015). The NGM SElect kit incorporates an additional STR, the SE33, to the mentioned above (Applied Biosystems, 2015).

The Province of Azuay is one of the 24 provinces forming up the Republic of Ecuador. The administrative capital city of Azuay is Cuenca, which is also the largest and most populated city of this province. Ecuadorian individuals originated from a racial miscegenation among ancestral indigenous groups with Spanish Caucasoid settlers and African descendants (Gaviria et al., 2013).

In addition to technical validation, the implementation of STRs requires population studies that include estimating various statistical parameters for forensic studies. At the intrapopulation level, the frequencies should be estimated as allelic frequencies and should verify the fact that the population in which the genetic analysis system will be used is in HardyWeinberg equilibrium, since this allows the use of the binomial squared formula to estimate the frequency of genotypes from allele frequencies. The associations between pairs of loci should be ruled out the linkage disequilibrium (DL), which allows the use of product rule in order to estimate the frequency of genetic profiles. In addition, it is convenient to estimate statistical parameters of forensic interest that indicates the expected utility a priori for each locus and for the genetic system such as: heterozygosity $\left(H_{\mathrm{E}}\right)$, power of exclusion $(\mathrm{PE})$, power of discrimination (PD), polymorphic information content (PIC), and index of paternity (IPT). On the other hand, at the inter-population level the validation of STRs usually includes the comparison with other populations to establish their genetic relationships, structure and even the knowledge of their origins (Martínez et al., 2016).

In summary, the forensic parameters and the population validation enable these systems to be used to estimate the frequency of a genetic profile, or to calculate the paternity probability in a criminal law case; when the alleged father and son agree on a paternity test. For this purpose, various population studies have been carried out and many databases have been generated throughout the world using STRs (Martínez et al., 2016).

Genetics and Molecular Research 16 (3): gmr16039797 
Yet, there is no information published about gene frequencies of multiallelic loci in the population of Azuay, Ecuador. The present study describes the allele frequencies of fifteen and sixteen STR loci in this population.

\section{MATERIAL AND METHODS}

The blood used in the paternity test was obtained from unrelated individuals residing in Azuay, Ecuador, through venipuncture and its collection in FTA classic cards. Later, these cards were perforated with a 1.2-mm micropuncher to obtain the DNA for the next step, the PCR amplification.

The PCR amplification of the first 15 genetic markers was made by using the NGM kit. Then, the NGM Select Kit was employed (including the SE33) for the amplification of 16 STRs.

The amplified samples were placed in the ABI3500 genetic analyzer and the Data Collection software helped to obtain the capylar electrophoresis results that were analyzed by the GenneMapper-IDX software.

\section{Statistical analysis}

The allele frequencies were determined and adjusted to the genotypic frequencies with EHW for each STR. The statistical parameters of forensic interest were determined using the PowerStats and GDA Softwares.

\section{RESULTS AND DISCUSSION}

The allele frequencies of the 16 autosomal STRs were estimated and included in the SElect NGM. Although they are the most basic parameters, the allele frequencies are the most useful data employed by forensic geneticists for biostatistic interpretations of each paternity test and for forensic cases when there is an agreement. Among them, a minimum of allele frequency is essential to interpret cases of null or rare alleles that can be used as a benefit for the accused (Martínez et al., 2016).

In the processes of identifying or analyzing biological ties of kinship for forensic purposes, it is necessary to have the largest number of markers with the highest probability of discrimination to avoid random collation. In this case study, there are 9 markers that are highly polymorphic and among them, there is the SE33 that shows the highest degree of polymorphic information, although this is a high molecular weight marker that is present in many commercial kits. Therefore, in cases where a small amount of amplifiable DNA is obtained, either because of the intrinsic condition of the samples' type (number of nucleated cells) or quality, which is mainly involved in the degree of degradation of the same DNA and/ or the presence of inhibitors, it will partially amplify or not, being the partial amplification the greatest risk, making it difficult to distinguish the homozygous state.

In the results obtained with the analyzed markers, the largest number of alleles can be observed in the markers with the highest PIC: D21S11, D16S539, D2S1338, D19S433, D18S51, FGA, D1S1656, and D12S391. In addition, SE33 was analyzed in certain samples, showing as a result a high PIC. In fact, the highest one because of its great polymorphism capacity. Likewise, these markers are those providing the highest probability of discrimination and the lowest probability of coincidence (Table 1).

Genetics and Molecular Research 16 (3): gmr16039797 
Table 1. Structure of the population at the level of heterozygosity of 15 markers not including SE33.

\begin{tabular}{l|c|c|c}
\cline { 1 - 3 } ALL population & HE & HO & f \\
\cline { 1 - 3 } Locus & & & 0.711111 \\
\hline D8S1179 & 0.770675 & 0.861111 & -0.026300 \\
\hline D21S11 & 0.839106 & 0.677778 & -0.002778 \\
\hline D3S1358 & 0.675905 & 0.666667 & 0.014091 \\
\hline TH01 & 0.676168 & 0.688889 & 0.127070 \\
\hline D16S539 & 0.788889 & 0.850000 & -0.013826 \\
\hline D2S1338 & 0.838440 & 0.805556 & 0.031277 \\
\hline vWA & 0.831492 & 0.733333 & -0.044216 \\
\hline D18S51 & 0.702368 & 0.855556 & -0.000290 \\
\hline FGA & 0.855308 & 0.833333 & 0.025373 \\
\hline D2S441 & 0.854968 & 0.594444 & 0.038118 \\
\hline D22S1045 & 0.617936 & 0.516667 & 0.108165 \\
\hline D1S1656 & 0.579155 & 0.683333 & 0.019287 \\
\hline D12S391 & 0.696735 & 0.861111 & 0.014632 \\
\hline All & 0.873863 & 0.805556 & 0.013887 \\
\hline SE33* & 0.816868 & 0.742963 & 0.024013 \\
\hline
\end{tabular}

\section{Hardy-Weimberg equilibrium and linkage imbalance}

When analyzing the Hardy-Weimberg equilibrium, it is observed that at a level of 0.05 there is no equilibrium in the markers D8S1179, D16S539, and $S E 33$, but when the limit is 0.01 , the only one that has a highly significant imbalance is the D16S539 marker (Table 2).

\begin{tabular}{|c|c|c|}
\hline Population \# 1 (Azuay) of 180 individuals & \multirow[t]{2}{*}{ Prob } & \multirow[t]{2}{*}{ Locus combination } \\
\hline Runs & & \\
\hline $3200^{*}$ & $0.035000^{*}$ & D8S1179* \\
\hline 3200 & 0.481875 & D21S11 \\
\hline 3200 & 0.946250 & D3S1358 \\
\hline 3200 & 0.730625 & TH01 \\
\hline $3200 *$ & $0.001250^{*}$ & D16S539* \\
\hline 3200 & 0.757500 & D2S1338 \\
\hline 3200 & 0.286250 & D19S433 \\
\hline 3200 & 0.350000 & vWA \\
\hline 3200 & 0.941875 & D18S51 \\
\hline 3200 & 0.402500 & FGA \\
\hline 3200 & 0.379375 & D2S441 \\
\hline 3200 & 0.058125 & D22S1045 \\
\hline 3200 & 0.633125 & D10S1248 \\
\hline 3200 & 0.545000 & D1S1656 \\
\hline 3200 & 0.618750 & D12S391 \\
\hline \multicolumn{3}{|l|}{ Population \# 1 (Azuay) of 89 individuals } \\
\hline Runs & Prob & Locus combination \\
\hline $3200 *$ & $0.033750^{*}$ & SE33* \\
\hline
\end{tabular}

*Significative probability to Hardy-Weimberg disequilibrium.

In the case of linkage disequilibrium, there is a very significant imbalance in the D16S539 marker that can be observed, and could be expected in populations, where historically, there have been large foreign components or in cases of miscegenation (Loh et al., 2013).

\section{Deficit and excess heterozygotes in the study population}

When observing the analized makers it can be seen that a total of 5 markers have 
excess of heterozygotes while the rest have heterozygotes deficit, being D16S539 the marker with the greatest value of heterozygotes deficit. (Table 1). Likewise, heterozygosity as a value is the highest in the most polymorphic markers, except for the D16S539 marker (Frequency Table 3). The general tendency of a slight heterozygote deficit is observed.

Table 3. Allelic frequencies, forensic parameters and of genetic structure in the population of Azuay.

\begin{tabular}{|c|c|c|c|c|c|c|c|c|c|c|c|c|c|c|c|c|}
\hline $\begin{array}{l}\text { Alleles } \\
6\end{array}$ & D8S11791 & D21S111 & D3S1358 1 & \begin{tabular}{|l|} 
THO111 \\
03379
\end{tabular} & D16S5391 & D2S13381 & D19S4331 & vWA 1 & DI8S511 & $\mathrm{FGAI}$ & D2S441 & D22S1045 & DI0S1248 & DIS1656 & D12S391 & SE33 \\
\hline$\frac{6}{7}$ & & & & 0.0 .3379 & & & & & & & & & & & & \\
\hline$\frac{8}{9}$ & \begin{tabular}{l|l}
0.0027 \\
0.0277 \\
\end{tabular} & & & $\begin{array}{l}0.0357 \\
0.0495\end{array}$ & $\begin{array}{l}0.0055 \\
0.2225 \\
\end{array}$ & & & & & & 0.027 & & & & & \\
\hline 9.2 & & & & & & & 0.0027 & & & 0.0027 & 0.0027 & & & & & \\
\hline$\frac{9.3}{10}$ & & & & 0.1429 & & & & & & & & & & & & \\
\hline$\frac{11}{11}$ & 0.1154 & & & 0.0027 & 0.26075 & & 0.0165 & & $\frac{0.0163}{0.0220}$ & & 0.5632 & 0.0275 & & 0.0139 & & 0.0056 \\
\hline 11.3 & & & & & & & & & & & 0.0275 & & & & & \\
\hline$\frac{12}{12.2}$ & 0.1538 & & 0.0027 & & 0.2418 & & 0.0 .0302 & 0.0027 & 0.0687 & & 0.0165 & 0.0027 & 0.0137 & 0.0639 & & 0.0112 \\
\hline 13 & 0.3791 & & 0.0027 & & 0.0797 & & 0.2170 & 0.0082 & 0.1044 & & 0.0110 & 0.0027 & 0.2335 & 0.1306 & & \\
\hline$\frac{13.2}{133}$ & 0027 & & & & & & 0.1126 & & & & & & & & & \\
\hline 14 & 0.2060 & & 0.0412 & & 0.0165 & & 0.2857 & 0.0192 & 0.2720 & & 0.1429 & 0.0055 & 0.4203 & 0.1139 & & 0.0337 \\
\hline$\frac{14.2}{15}$ & 0.0604 & & 0.4753 & & 0.0027 & & $\begin{array}{l}0.0467 \\
0.101 \\
\end{array}$ & 00797 & 01538 & & 0.0275 & 04066 & 02637 & 01361 & 0,0055 & 000566 \\
\hline$\frac{15.2}{15.2}$ & & & 年 & & 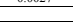 & & 0.0742 & 0.079 & 0.1500 & & 0.0275 & 0.4000 & 0.2037 & 0.1501 & 0.0050 & 0.0306 \\
\hline$\frac{15.3}{16}$ & 0.0165 & & 0.2720 & & & 0.0082 & 0.0302 & 0.3846 & 0.1099 & & & 0.5000 & 0.0632 & 0.0111 & 0.0357 & 0.0674 \\
\hline$\frac{16.2}{16.3}$ & & & & & & & 0.0302 & & & & & & & 0.0528 & & \\
\hline 17 & & & 0.1538 & & & 0.1621 & & 0.3626 & 0.1236 & 0.0110 & & 0.0495 & 0.0055 & 0.0583 & 0.0247 & 0.1236 \\
\hline$\frac{17.2}{173}$ & & & & & & & 0.0027 & & & & & & & 0 & & \\
\hline 18 & & & 0.0467 & & & 0.0824 & & 0.1016 & 0.0659 & 0.0137 & & 0.0055 & & $\begin{array}{l}0.1659 \\
0.0056\end{array}$ & 0.0 .082 & 0.0506 \\
\hline 18.3 & & & & & & & & & & & & & & 0.0361 & 0.0027 & \\
\hline$\frac{19}{192}$ & & & 0.0055 & & & 0.2280 & & 0.0357 & 0.0192 & 0.0495 & & & & & 0.1868 & $\frac{0.1011}{0.0112}$ \\
\hline$\frac{19.3}{20}$ & & & & & & 0.1951 & & 0.0055 & $0,1 / 1$ & 00330 & & & & 0.0111 & 0.0275 & 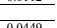 \\
\hline 21 & & & & & & 0.0 .1947 & & & 0.0165 & 0.0742 & & & & & 0.1016 & $\begin{array}{l}0.0449 \\
0.0169 \\
\end{array}$ \\
\hline$\frac{21.2}{22}$ & & & & & & 0.0440 & & & 0002 & 0082 & & & & & 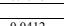 & 0.0056 \\
\hline 22.2 & & & & & & 0.0440 & & & 0.0082 & 0.0824 & & & & & 0.0412 & 0.0112 \\
\hline$\frac{23}{23.2}$ & & & & & & 0.1868 & & & 0.0055 & 0.1291 & & & & & 0.0357 & 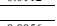 \\
\hline 24 & & & & & & 0.0467 & & & 0.0027 & 0.1978 & & & & & 0.0137 & 0.0056 \\
\hline 24.2 & & & & & & 0.0165 & & & & 0.2280 & & & & & 0.0110 & 0.0169 \\
\hline 25.2 & & & & & & 00055 & & & & 01538 & & & & & & 0.0337 \\
\hline 26.2 & & & & & & 0.0053 & & & & 0.1538 & & & & & & 0.0169 \\
\hline$\frac{27}{27.2}$ & & 0.0027 & & & & & & & & 0.0165 & & & & & & 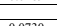 \\
\hline 28 & & 0.0742 & & & & & & & & 0.0082 & & & & & & 0.0730 \\
\hline 28.2 & & & & & & & & & & & & & & & & 0.0955 \\
\hline 29.2 & & 0.1511 & & & & & & & & & & & & & & 00674 \\
\hline 30 & & 0.2610 & & & & & & & & & & & & & & 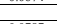 \\
\hline$\frac{30.2}{31}$ & & 0.038 & & & & & & & & & & & & & & 0.0787 \\
\hline 31.2 & & $\begin{array}{l}0.0097 \\
0.1978 \\
\end{array}$ & & & & & & & & & & & & & & 0.0506 \\
\hline$\frac{32}{32.2}$ & & $\frac{0.0110}{0.1346}$ & & & & & & & & & & & & & & 0.0112 \\
\hline 33.2 & & 0.0604 & & & & & & & & & & & & & & 0.0056 \\
\hline 34.2 & & 0.0027 & & & & & & & & & & & & & & 0.0056 \\
\hline Homozygotes & 0.29 & $\frac{0.0079}{0.14}$ & 0.32 & 034 & & 0.15 & & 026 & 0.14 & 016 & 041 & 048 & 033 & 014 & 819 & \\
\hline Heterozygote & 0.71 & 0.86 & 0.68 & 0.66 & 0.69 & 0.85 & 0.20 & 0.20 & $\frac{.14}{0.86}$ & 0.84 & 0.419 & 0.48 & 0.52 & 0.14 & 0.81 & $\frac{0.12}{0.88}$ \\
\hline $\begin{array}{l}\text { Total Allel } \\
\text { Probboblitit }\end{array}$ & 364 & 364 & 364 & 364 & 364 & 364 & 364 & 364 & 364 & 364 & 364 & 364 & 364 & 360 & 364 & 178 \\
\hline $\begin{array}{l}\text { Probabablity of } \\
\text { coincidence }\end{array}$ & 0.0852 & 0.0509 & 0.1618 & 0.1539 & 0.0749 & 0.0509 & 0.0633 & 0.1524 & 0.0369 & 0.0404 & 0.1623 & 0.2501 & $0.147 / 2$ & 0.0348 & 0.0664 & 0.0213 \\
\hline $\begin{array}{l}\text { Power of } \\
\text { piscriving }\end{array}$ & 0.9148 & 0.9491 & 0.8382 & 0.8461 & 0.9251 & 0.9491 & 0.9467 & 0.8476 & 0.9631 & 0.9596 & 0.8377 & 0.7499 & 0.8528 & 0.9652 & 0.9396 & 0.9787 \\
\hline $\begin{array}{l}\text { Dissrnmination } \\
\text { Polymorphic } \\
\text { Information }\end{array}$ & 0.7392 & 0.8171 & 0.6224 & 0.6185 & 0.7542 & 0.8164 & 0.8080 & 0.6527 & 0.8385 & 0.8353 & 0.5731 & 0.4960 & 0.6411 & 0.8582 & 0.7919 & 0.9271 \\
\hline Probability of & 0.4507 & 0.7199 & 0.3919 & 0.3760 & 0.4165 & 0.6981 & 0.6031 & 0.4866 & 0.7090 & 0.6658 & 0.2766 & 0.2075 & 0.4000 & 0.7169 & 0.6134 & 0.7475 \\
\hline Typical & 1.7500 & 3.6400 & 1.5424 & 1.4918 & 1.6250 & 3.3704 & 2.5278 & 1.8958 & 3.5000 & 3.0333 & 1.2133 & 1.0460 & 1.5690 & 3.6000 & 2.6000 & 4.0455 \\
\hline $\begin{array}{l}\text { Minimum } \\
\text { allele }\end{array}$ & 0.0151 & 0.0170 & 0.0147 & 0.0146 & 0.0149 & 0.0168 & 0.0161 & 0.0153 & 0.0169 & 0.0165 & 0.0139 & 0.0134 & 0.0148 & 0.0171 & 0.0162 & 0.0339 \\
\hline $\begin{array}{l}\text { Irequency } \\
\text { Wardy- } \\
\text { Weiberg } \\
\text { Equilibrium }\end{array}$ & 0.0350 & 0.4819 & 0.9463 & 0.7306 & 0.0013 & 0.7575 & 0.2863 & 0.3500 & 0.9419 & 0.4025 & 0.3794 & 0.0581 & 0.6331 & 0.5450 & 0.6188 & 0.0338 \\
\hline
\end{tabular}

\section{ACKNOWLEDGMENTS}

The authors present our acknowledgments to the Directors of the Universidad Católica de Cuenca (Cuenca-Ecuador) for the help and the economic support provided for the culmination of this investigative work, also to all the individuals who authorized the use of their samples for this study.

Genetics and Molecular Research 16 (3): gmr16039797 


\section{REFERENCES}

Applied Byosistems (2015). User guide. AmpFISTR ${ }^{\circledR}$ NGM $^{\mathrm{TM}}$ PCR Amplification Kit.

Butler JM (2005). Forensic DNA typing: Biology, Technology, and Genetics of STR Markers. Elsevier, Oxford.

Butler JM (2006). Genetics and genomics of core short tandem repeat loci used in human identity testing. J. Forensic Sci. 51: 253-265. https://doi.org/10.1111/j.1556-4029.2006.00046.x

Cifuentes L, Jorquera H, Acuña M, Ordóñez J, et al. (2008). Allele frequencies for 12 autosomal short tandem repeat loci in two Bolivian populations. Genet. Mol. Res. 7: 271-275. https://doi.org/10.4238/vol7-1gmr368

Gaviria A, Zambrano AK, Morejon G, et al. (2013). Twenty two autosomal microsatellite data from Ecuador (Powerplex Fusion). Forensic Sci. International. Genet. Suppl. Ser. 4: 330-333. https://doi.org/10.1016/j.fsigss.2013.10.169

Loh PR, Lipson M, Patterson N, Moorjani P, et al. (2013). Inferring admixture histories of human populations using linkage disequilibrium. Genetics 193: 1233-1254. https://doi.org/10.1534/genetics.112.147330

Martínez VM, Aguilar JA, Inclán A, et al. (2016). Parámetros forenses del sistema Powerplex ${ }^{\circledR} 21$ (Promega Corp.) en población mestiza del occidente de México. Revista Española de Medicina Legal. 42: 10-16. https://doi.org/10.1016/j. reml.2015.03.001

Genetics and Molecular Research 16 (3): gmr16039797 